\title{
T Cell Subsets, Epitope Mapping, and HLA-Restriction in Patients with Allergic Bronchopulmonary Aspergillosis
}

\author{
Bela Chauhan, ${ }^{\star}$ Alan P. Knutsen, ${ }^{\ddagger}$ Patricia S. Hutcheson, ${ }^{\star}$ Raymond G. Slavin, ${ }^{\star}$ and Clifford J. Bellone ${ }^{\S}$ \\ $*$ Departments of Internal Medicine, ${ }^{\ddagger}$ Pediatrics, and ${ }^{\S}$ Molecular Microbiology and Immunology, St. Louis University School of Medicine, \\ St. Louis, Missouri 63104
}

\begin{abstract}
Allergic bronchopulmonary aspergillosis (ABPA) is a hypersensitivity lung disease characterized by Aspergillus fumigatus (Af) colonization, IgE and IgG anti-Af antibodies, pulmonary infiltrates, bronchiectasis, and pulmonary fibrosis. Little is known regarding $\mathrm{T}$ cell responses and their role in the pathogenesis of ABPA. To examine $T$ cell reactivity to Af antigens, $T$ cell clones (TCC) specific to the Asp f 1 antigen, an 18-kD protein of Af, were established from the peripheral blood of three ABPA patients. The majority of TCC isolated from ABPA patients, and specific for the Asp f 1 allergen of Af, are IL-4 producing CD4+ cells of the Th2 phenotype. Further analysis in this study revealed that the majority of TCC reacted to mainly two epitopes of Asp f 1, while the remaining TCC reacted to three additional "minor" epitopes. Blocking studies using monoclonal antibodies specific for class II HLA-D region gene products showed that most TCC, 19/21, were restricted by HLA-DR molecules, and the remaining two clones by HLA-DP molecules. The use of a panel of HLA-matched and mismatched EBVtransformed $B$ cells as antigen presenting cells revealed that the HLA-DR restriction was mediated exclusively by either the HLA-DR2 or HLA-DR5 alleles. Genotyping of DRB1 gene products showed that class II presentation for most clones was not restricted to a single allele, representing DRB1 gene products of either HLA-DR2 or DR5. These studies offer insight into the cellular and molecular determinants which contribute to the immunopathophysiology of ABPA. ( $J$. Clin. Invest. 1996. 97:2324-2331.) Key words: allergic bronchopulmonary aspergillosis $\bullet T$ cell clones $\bullet$ HLA-restriction - epitope mapping • cytokines
\end{abstract}

\section{Introduction}

Allergic bronchopulmonary aspergillosis (ABPA $)^{1}$ is a hypersensitivity lung disease characterized by Aspergillus fumigatus (Af) colonization, pulmonary infiltrates, bronchiectasis, pulmonary fibrosis, elevated total $\mathrm{IgE}, \mathrm{IgG}$ and $\mathrm{IgE}$ anti-Af anti-

Address correspondence to Clifford J. Bellone, Ph.D., St. Louis University Health Sciences Center, Department of Molecular Microbiology and Immunology, 1402 S. Grand Boulevard, St. Louis, MO 63104. Phone: 314-577-8449; FAX: 314-773-3403; E-mail: bellonec@wpogate.slu.edu

Received for publication 20 April 1995 and accepted in revised form 26 February 1996.

J. Clin. Invest.

(C) The American Society for Clinical Investigation, Inc. 0021-9738/96/05/2324/08 \$2.00

Volume 97, Number 10, May 1996, 2324-2331 bodies, and eosinophilia. These features are generally associated with the occurrence of allergen specific $\mathrm{T}$ helper type 2 (Th2) CD4+ lymphocytes (1-3). Our group has recently shown that $\mathrm{IgE}$ is made to a number of Af proteins (4), including the dominant $18 \mathrm{kD}$ Asp f 1 protein which is thought to play a major role in the immunopathophysiology of ABPA. It is a secreted protein and potent ribotoxin that is cytotoxic to surrounding tissue. In addition, Asp $\mathrm{f} 1$ induces specific $\operatorname{IgE}$ that results in an immune-mediated inflammation and further exacerbation of lung injury. It is well documented that CD4+, IL-4 producing T-lymphocytes play a critical role in the induction of IgE immune responses and eosinophilia. We previously reported the establishment of $\mathrm{T}$ cell lines reactive to purified Asp $\mathrm{f} 1$ from the peripheral blood of ABPA patients (5). It was clear from those studies that virtually all of the Asp f $1 \mathrm{~T}$ cells from these patients produced significant amounts of IL-4 and with rare exception little or no IFN- $\gamma$, thus revealing an almost exclusive Th2 like profile. The dominance of this subset in response to Asp f 1 protein is likely to play a major role in the pathophysiology of ABPA.

In this study we have extended our prior findings by establishing Asp f 1-specific TCC to examine their cytokine profiles, epitope specificity, and HLA class II restriction. We show that the majority of clones from three patients are directed primarily to two dominant Asp f 1 epitopes, all restricted by either HLA-DR2 or HLA-DR5. Within either of these serotypes, class II involvement in Asp f 1 antigen presentation was restricted to one or a few of the alleles of a given DRB1 genotype. These studies provide new insights into the cellular and molecular mechanisms of the immune response known to play an important role in the immunopathophysiology of ABPA.

\section{Methods}

Patients. Three asthmatic patients (BM, MA, and MK) with ABPA from the St. Louis University allergy clinic were used in this study. Institutional Review Board approval was granted, and informed consent was obtained for each patient. All these patients fulfilled criteria for the diagnosis of ABPA as outlined by Patterson et al. (6). In these asthmatic patients ABPA was diagnosed by the presence of recurrent wheezing, presence of new chest radiographic infiltrates, peripheral blood eosinophilia, immediate Af skin reactivity, positive precipitating antibody against Af antigens, elevated serum IgE greater than $1000 \mathrm{IU} / \mathrm{ml}, \mathrm{IgE}$ and $\mathrm{IgG}$ anti-Af antibody by ELISA as well as $\mathrm{IgE}$ and IgG anti-Asp $f 1$ antibodies by Western blotting. HLA typing of the patients (BM - DR2, DR7, DQW6, DQW2; MK - DR2, DR4,

1. Abbreviations used in this paper: ABPA, Allergic bronchopulmonary aspergillosis; Af, Aspergillus fumigatus; APC, Antigen presenting cells; CM, complete medium; HTC, homozygous typing cell lines; TCC, T cell clones; TCR, T cell receptor; Th1, Type- 1 helper T cell; Th2, Type-2 helper T cell. 
DQW6, DQW3; MA - DR1, DR5, DQW1, DQW2) was performed by the HLA facility at St. Louis University. At the time blood was drawn, two patients BM and MA were in remission and the third patient, MK, was receiving prednisone for exacerbation of her disease.

Antibodies and cell lines. Murine monoclonal antibodies antiHLA-DR (L243), anti-HLA-DP (B7/21), and anti-HLA-DQ (1a3) against human MHC class II framework determinants were all purchased from Leinco Technologies, Inc. (St. Louis, MO). Anti-HLA class I antibody (W6/32) and heterozygous EBV-B transformed B-cell lines were gifts of Dr. T. Mohanakumar (Washington University, St. Louis, MO). Homozygous typing cells lines (HTC) were gifts from Dr. David Chaplin (Washington University, St. Louis, MO). Homozygous genotyped EBV-transformed B cell lines were purchased from John Hopkins Laboratories (Baltimore, MD).

Antigen. A. fumigatus mycelium and spore components from long-term stationary cultures were provided by Greer Laboratories (Lenoir, NC). Strains producing sufficient amounts of Asp f 1 were identified by ELISA assays using the 4A6 monoclonal anti-Asp f 1 antibody (7). Asp f 1 purification was performed by affinity chromatography (data not shown).

Synthetic peptides. A panel of 10 peptides was synthesized according to published Asp f 1 sequence (8) by Chiron Mimotop (Australia). Twenty-mer amino acid peptides which overlapped by five amino acids were constructed for the entire length of the protein. Peptides were titrated over a concentration range of $1-20 \mu \mathrm{g} / \mathrm{ml}$ for lymphocyte proliferation assays.

Generation of Asp f 1-specific TCC clones. Asp f 1 and tetanus toxoid (TT) specific T cell clones were generated as described (9). Briefly, $2 \times 10^{6} \mathrm{PBMC} /$ well were stimulated with optimal antigen concentrations (Asp f 1 5-10 $\mu \mathrm{g} / \mathrm{ml}$, tetanus toxoid $50 \mathrm{LF} \mathrm{U} / \mathrm{ml}$ ) in complete media (CM) which consisted of RPMI 1640 supplemented with $12 \%$ pooled normal human serum (NHS), $2 \mathrm{mM}$ L-Glutamine, $25 \mathrm{mM}$ Hepes buffer, $100 \mu \mathrm{g} / \mathrm{ml}$ of penicillin and streptomycin, $1 \mathrm{mM}$ sodium pyruvate and $0.05 \mathrm{mM}$ 2-mercaptoethnol (all from GIBCO, Basel, Switzerland), and cultured for $5 \mathrm{~d}$ in 24-well flat bottomed culture plates (Costar, Cambridge, MA). Subsequently, recombinant IL-2 (25 U/ml) was added and kept in culture for an additional $5 \mathrm{~d}$. Viable $\mathrm{T}$ cell blasts were then separated by a Ficoll/Hypaque density gradient (Pharmacia Fine Chemicals, NJ) and subsequently cloned into Terasaski plates (Robbins Scientific, Sunnyvale, CA) at 0.3 cells/well along with $1 \times 10^{4} \mathrm{EBV}$-transformed B-cells in CM containing $25 \mathrm{U} / \mathrm{ml}$ of rIL-2 and an optimal concentration of Asp $\mathrm{f} 1$ or TT antigen. After incubation for $7 \mathrm{~d}$ at $37^{\circ} \mathrm{C}$ in a humidified atmosphere of $5 \% \mathrm{CO}_{2}$, growing cells were transferred to fresh medium $(0.2 \mathrm{ml})$ containing $25 \mathrm{U} / \mathrm{ml}$ of rIL-2 and irradiated autologous feeder cells $\left(1 \times 10^{5} / \mathrm{ml}\right)$ in 96 -well plates. After $2 \mathrm{wk}$, expanding clones were transferred to 24 -well plates containing an appropriate concentration of rIL-2 and feeders. All clones received fresh rIL-2 every 3-4 d, and irradiated feeders once a week. After about 10-12 d most clones had produced enough cells to test for antigen specificity in proliferation assays using either purified Asp $\mathrm{f} 1$ or tetanus toxoid (Connought Lab., Toronto, Canada).

Proliferation assay. To test TCC in proliferation assays, antigen and rIL-2 were removed $10-14$ and 2-4 d, respectively, prior to the assay. T cells were washed three times in CM to remove all rIL-2 and assayed by culturing $3 \times 10^{4}$ cells/well in 96 well U-bottom trays in the presence of specific antigen and $3 \times 10^{4}$ cells/well irradiated EBV-transformed B cells as antigen presenting cells (APC). Optimal concentration of whole antigen and peptides were achieved by performing dose response assays. Cultures were incubated for $48-72 \mathrm{~h}$, pulsed for $16 \mathrm{~h}$ with $1.0 \mathrm{uCi}$ of $\left[{ }^{3} \mathrm{H}\right] \mathrm{TdR}$ (ICN) and harvested onto glass filter paper (Cambridge Technology, Inc., Watertown, MA). Proliferation was measured as $\left[{ }^{3} \mathrm{H}\right] \mathrm{TdR}$ incorporation using liquid scintillation spectroscopy. Results were expressed as the mean counts per minute (CPM) for triplicate cultures. Stimulating indices were calculated by dividing incorporation in cultures containing antigen by cultures in the absence of antigen. Antigens used in these assays included either purified Asp f 1 or tetanus toxoid (Connought Lab., Toronto, Canada).
Quantitation of IL-2, IL-4, and IFN- $\gamma$ in TCC supernatants. To prepare supernatants for cytokine measurements, TCC were rested, washed, and stimulated with the appropriate antigen in 96-well tissue culture plates at $3 \times 10^{4}$ cell per well with an equal number of irradiated autologous feeder cells. Supernatants after $48 \mathrm{~h}$ were pooled from identical wells, centrifuged, filtered through $0.22 \mu \mathrm{m}$ filters, and stored in aliquots at $-70^{\circ} \mathrm{C}$ until used.

For the measurement of IL-2 in TCC supernatant, an immunoassay kit (Biosource International, CA) was used according to manufacturer's instructions.

IFN- $\gamma$ levels in supernatant were quantitated using a sandwich ELISA with antibodies provided by Dr. R. Schreiber, Washington University, St. Louis. Briefly, monoclonal antibody K3 (neutralizing mouse anti-human IFN- $\gamma$ antibody of IgG2a isotype) was used at 3.5 $\mu \mathrm{g} / \mathrm{ml}$ in carbonate buffer ( $\mathrm{pH}$ 9.6) to coat immulon II plates (Dynatech, Alexandria, VA). Each plate was coated with $100 \mu \mathrm{l} /$ well of diluted antibody and incubated overnight at $4{ }^{\circ} \mathrm{C}$. After washing with PBS, $100 \mu \mathrm{l}$ aliquots of standards and samples diluted in RPMI with $10 \%$ FCS were added to the ELISA plates. Plates were incubated for $2 \mathrm{~h}$ at room temperature. After washing the plates, a polyvalent antihuman IFN- $\gamma$ antibody diluted in RPMI with $10 \%$ FCS was added in $100 \mu \mathrm{l} /$ well. Plates were incubated for another one hour at room temperature, washed again, and a peroxidase conjugated anti-human IgG antibody was added in $100-\mu l$ aliquots to the ELISA plates. Plates were then incubated for $45 \mathrm{~min}$ at room temperature, and washed. ABTS substrate in citric acid buffer $(\mathrm{pH} 4.6)+0.1 \% \mathrm{H}_{2} \mathrm{O}_{2}$ was added to develop the assay. After 15-30 min of incubation in the dark, plates were read on an ELISA reader. Standards were run with each assay and samples were tested in duplicate.

IL-4 production was measured using an ELISA described by Knutsen et al. (5). Briefly 96-well immulon II (Dynatech, Alexandria, VA) plates were coated with a mouse anti-human IL-4 monoclonal antibody (PharMingen, San Diego, CA). Plates were washed with PBS containing $0.05 \%$ Tween 20 , and blocked with PBS containing $5 \%$ BSA (Sigma Chemical Co., St. Louis, MO). The culture supernatant and human rIL-4 standard (R and D System, Minneapolis, MN) were diluted in PBS containing 2\% BSA and were added to the coated plates. Plates were incubated with biotinylated rat anti-human IL-4 monoclonal antibody (PharMingen, San Diego, CA) followed by avidin conjugated horseradish peroxidase (Vector Laboratories, Inc., Burlingame, CA). Washing between steps was performed with PBS containing $0.05 \%$ Tween 20 . After 30 min incubation period at room temperature the reactions were stopped with $50 \mu \mathrm{l}$ of $2 \mathrm{~N} \mathrm{HCL}$ and the plates were read on an ELISA reader.

\section{Results}

Characterization of Asp f 1 specific TCC. To begin studies toward an understanding of the cellular mechanisms responsible for the high levels of IgE anti-Asp $f 1$ antibodies, a panel of Asp f 1-specific TCC were generated from three ABPA patients. A total of twenty-one TCC were generated from the three patients. All the clones proliferated in response to Asp $\mathrm{f}$ 1 antigen when presented by autologous irradiated EBV-B cells. The clonality and specificity of the $\mathrm{T}$ cells was indicated by the proliferation assay results shown in Fig. $1 A$. All of the Asp $\mathrm{f} 1$ generated TCC responded in a dose dependent manner by the addition of increasing amounts of purified Asp $\mathrm{f} 1$. No proliferation was seen when tetanus toxoid was substituted for Asp f 1 in a dose related manner. Proliferation was not due to nonspecific mitogenic effects of Asp $\mathrm{f} 1$ since tetanus toxoid clones generated from the same subjects did not show any significant response to the Asp $\mathrm{f} 1$ antigen but responded in a dose dependent manner to tetanus toxoid (Fig. $1 B$ ). Flow cytometric analyses demonstrated that all Asp f 1-specific clones 

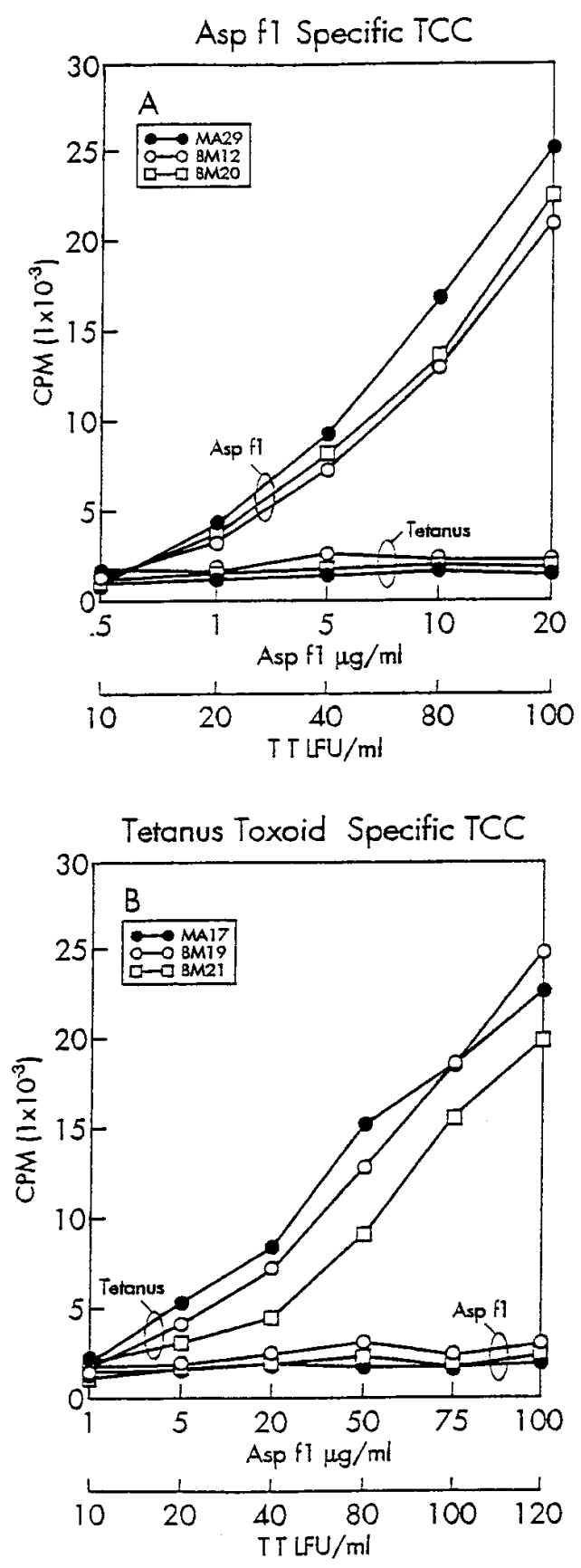

Figure 1. Determination of TCC specificity using specific and non specific antigen. $(A)$ Asp f 1 -specific TCC $\left(3 \times 10^{4} /\right.$ well $)$ were tested for their proliferative response in a dose dependent manner with Asp $\mathrm{f} 1$ or tetanus toxoid antigen in the presence of autologous APC $(3 \times$ $10^{4} /$ well). (B) Tetanus toxoid-specific TCC were tested as above. Values are given as CPM as determined by $\left[^{3}\right] \mathrm{TdR}$ incorporation.

used in this study were CD3+, CD4+, CD8-, and expressed the $\alpha \beta$ T cell receptor (TCR) (data not shown).

Cytokine profile. The cytokine secretion profiles of Asp $\mathrm{f}$ 1 - and TT-specific TCC are presented in Table I. Culture supernatants were tested for IL-2, IFN- $\gamma$, and IL-4 cytokines from 21 Asp f 1- and 6 TT-specific clones. Each cytokine was measured by an appropriate ELISA. The measurements of cytokine levels after specific stimulation of TCC with Asp f 1 re- vealed a high IL-4/IFN- $\gamma$ ratio (Th2 like pattern of cytokine production) for 17/21 clones. Maximal IL-4 and IL-2 production in these clones as measured in the culture supernatant was reached at $48 \mathrm{~h}$ after stimulation with Asp f 1 . The amounts of IL-2 in the next $12 \mathrm{~h}$ were consistently decreased while the IL-4 levels were not significantly altered (data not shown). These results are consistent with the nature of the Th2 population since proliferation of these cells is for the most part dependent upon autocrine IL-4 stimulation and therefore continued production of IL-4 $(5,10)$. The remaining four TCC displayed a

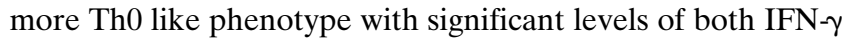
and IL-4 in the TCC supernatant after antigen stimulation (Table I).

To study whether the ability to produce high levels of IL-4 and little IFN- $\gamma$ and IL-2 was confined to allergen reactive TCC, the cytokine profiles of TT-specific clones from the same patients were examined. In marked contrast to the Asp f 1 clones, the TT-specific clones upon stimulation produced substantial amounts of IFN- $\gamma(850-3400 \mathrm{pg} / \mathrm{ml})$ whereas little to

Table I. Cytokine Production of Asp f 1 and TT specific T Cell Clones

\begin{tabular}{|c|c|c|c|c|c|}
\hline TCC & $\begin{array}{l}\text { Proliferative Response } \\
\quad\left(\mathrm{cpm} \times 10^{-3}\right)\end{array}$ & $\begin{array}{l}\text { Stimulation } \\
\text { Index }\end{array}$ & IL-4 & IFN- $\gamma$ & IL-2 \\
\hline & & & $\mathrm{pg} / \mathrm{ml}$ & $\mathrm{pg} / \mathrm{ml}$ & $\mathrm{pg} / \mathrm{ml}$ \\
\hline \multicolumn{6}{|c|}{ Asp f 1 Specific } \\
\hline BM1 & 18.3 & 30.5 & 900 & $<100$ & 235 \\
\hline BM2 & 18.7 & 26.7 & 440 & $<100$ & $<100$ \\
\hline BM4 & 15.3 & 21.8 & 560 & 480 & 400 \\
\hline BM8 & 12.6 & 42.0 & 620 & $<100$ & $<100$ \\
\hline BM11 & 24.7 & 27.4 & 660 & $<100$ & $<100$ \\
\hline BM12 & 11.3 & 12.5 & 310 & $<100$ & $<100$ \\
\hline BM19 & 11.0 & 27.5 & 3120 & 300 & 200 \\
\hline BM21 & 28.0 & 40.0 & 850 & $<100$ & $<100$ \\
\hline MA12 & 25.2 & 21.0 & 1170 & 245 & 150 \\
\hline MA18 & 17.5 & 19.4 & 290 & $<100$ & $<100$ \\
\hline MA29 & 11.9 & 14.8 & 500 & $<100$ & $<100$ \\
\hline MA35 & 19.9 & 32.6 & 250 & $<100$ & $<100$ \\
\hline MA38 & 25.4 & 28.2 & 410 & $<100$ & $<100$ \\
\hline MA49 & 21.8 & 19.8 & 350 & $<100$ & $<100$ \\
\hline MA52 & 23.2 & 33.1 & 650 & $<100$ & $<100$ \\
\hline MK12 & 10.5 & 13.1 & 440 & $<100$ & $<100$ \\
\hline MK28 & 9.5 & 23.7 & 930 & 250 & 390 \\
\hline MK32 & 14.3 & 11.9 & 650 & 380 & 220 \\
\hline MK35 & 19.7 & 16.4 & 440 & 125 & $<100$ \\
\hline MK38 & 13.7 & 17.1 & 230 & $<100$ & $<100$ \\
\hline MK50 & 29.6 & 26.9 & 840 & 520 & 350 \\
\hline \multicolumn{6}{|l|}{ TT Specific } \\
\hline ВMT7 & 22.4 & 24.8 & 178 & 1700 & 1284 \\
\hline BMT16 & 12.8 & 18.2 & $<100$ & 1140 & 340 \\
\hline BMT19 & 24.3 & 24.1 & $<100$ & 1600 & 472 \\
\hline MAT10 & 16.0 & 26.6 & $<100$ & 850 & 312 \\
\hline MAT18 & 9.5 & 10.5 & $<100$ & 1420 & 340 \\
\hline MAT25 & 14.0 & 20.0 & $<100$ & 3400 & 1350 \\
\hline
\end{tabular}

*For proliferation assays, Asp f 1 concentration was $10 \mu \mathrm{g} / \mathrm{ml}$ and tetanus toxoid concentration was $50 \mathrm{LF} \mathrm{U} / \mathrm{ml}$ for all clones tested. Supernatants were harvested at $48 \mathrm{~h}$ and assayed for the cytokine as indicated. 


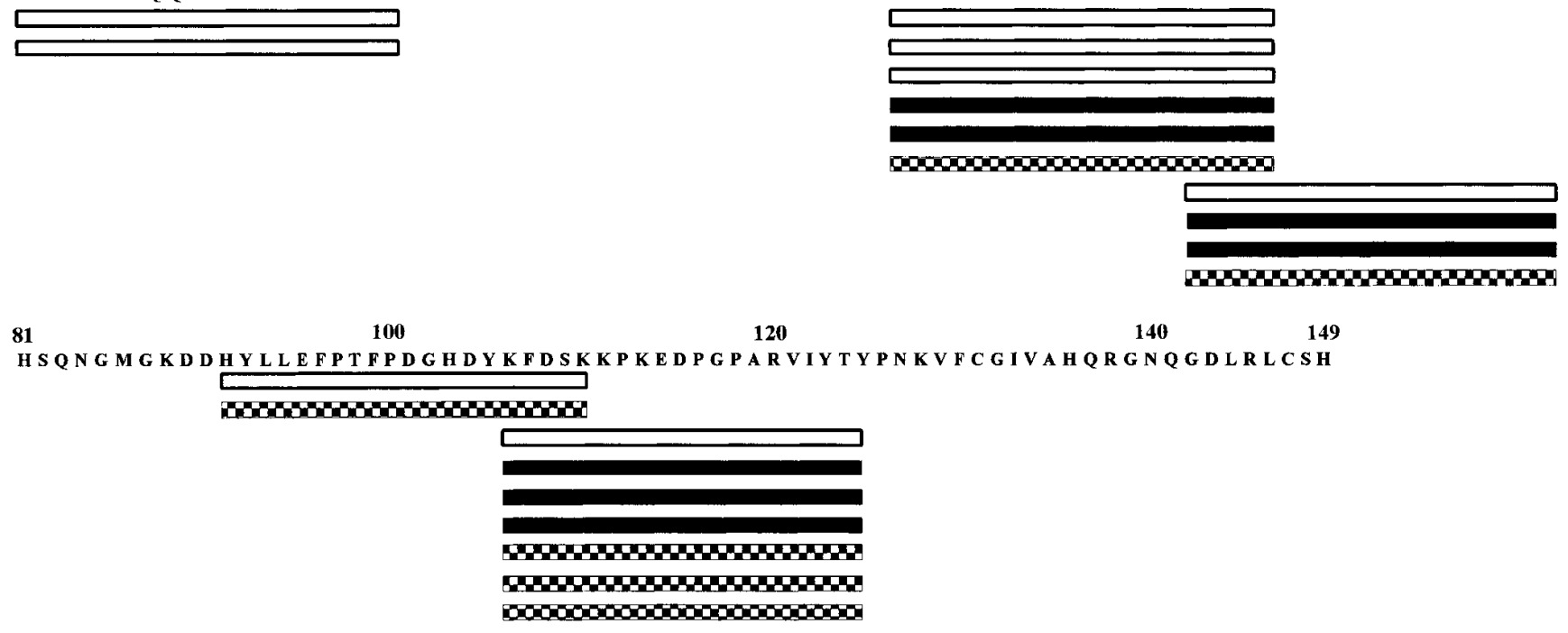

Figure 2. Schematic diagram of the amino acid sequence (single letter code) of Asp $\mathrm{f} 1$. The position of 20-mer peptides stimulating specific $\mathrm{T}$ cell clones are indicated by bars underneath the sequence. The different diagrammed bars represent the number and the donor patient (BM, open bars; MA, closed bars; MK, checkerboard bars) of the responding TCC.

undetectable levels of IL-4 were measured (Table I). IFN- $\gamma$ remained at high levels $72 \mathrm{~h}$ after antigen stimulation (data not shown).

Epitope mapping. To determine epitope specificity, the entire panel of 21 TCC was tested for antigen induced proliferation over a concentration range with 10 overlapping synthetic peptides that spanned the entire Asp f 1 molecule. This approach revealed five T cell-reactive peptides (see Fig. 2) which were independently verified using peptides generated by endoproteinase digestion of purified Asp f 1 (data not shown). The majority of TCC (13/21) were stimulated by two peptides, 46-65 and 106-125, while the remaining TCC reacted to peptides 1-20, 61-80, and 91-110 (see Fig. 2). TCC responded to their cognate, but not to irrelevant, peptides in a dose dependent manner (data not shown). In two regions reactive peptides overlapped but in both cases no cross reactivity was noted between the peptides for a given clone. This would indicate that at least two distinct epitopes are present within the regions defined by the overlapping peptides. Overall the results in the ABPA population indicate at least the involvement of two dominant epitopes in T cell responses to Asp $\mathrm{f} 1$.

\section{MHC class II restriction}

Inhibition of the proliferative responses of $T$ cells. To define the MHC class II molecules which act as restriction elements, monoclonal antibodies directed against framework determinants of HLA-class II molecules were used to block Asp f 1 induced TCC proliferation. For all inhibition assays, antibodies were added over a concentration range at the initiation of the cultures (11). Results of a typical inhibition assay in which antibodies specific for either DR, DP, or DQ molecules were used is shown in Fig. 3. The results of all inhibition assays are presented in (Table II). The analyses demonstrated that of 21 TCC tested, 19 clones were restricted by HLA-DR, two by HLA-DP, and none by HLA-DQ. Blockade of the proliferative response was not due to nonspecific toxic effects of the an- tibody preparations since no observed inhibition was noted except where the relevant class II antigens were present on the appropriate antigen presenting cells. Furthermore, no inhibition was seen when the class I antibody W6/32 was added to any of the proliferation assays (data not shown).

Restriction pattern of $T$ cell clones. Since most of the TCC were restricted by the products of the HLA-DR locus we next examined which of the DR serotypes in each patient were responsible for antigen presentation. To accomplish this, EBV-

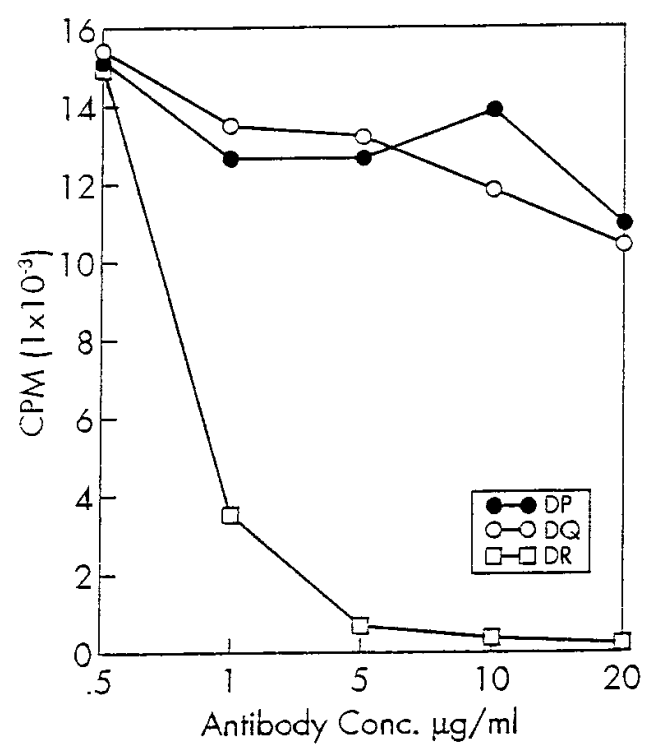

Figure 3. Class II MHC restriction of Asp f 1-specific T cell clones. The figure represents a typical blocking experiment using varying amounts of monoclonal anti-HLA-DR $(\square)$, anti-DP $(\bullet)$, and antiDQ $(\bigcirc)$ antibodies added at the initiation of the cultures. T cell proliferation assays were performed as described in Fig. 1. 
Table II. Inhibition of Asp f 1 Specific Proliferation of TCC by Anti-HLA Class II Monoclonal Antibodies

\begin{tabular}{|c|c|c|c|c|c|c|}
\hline \multirow[b]{2}{*}{$\mathrm{TCC}$} & \multicolumn{5}{|c|}{ PROLIFERATION CPM $\left(1 \times 10^{-3}\right)^{*}$} & \multirow[b]{2}{*}{$\begin{array}{l}\text { Percent } \\
\mathrm{Inh}^{\ddagger}\end{array}$} \\
\hline & No $\mathrm{Ab}$ & $\begin{array}{l}\text { Anti- } \\
\text { HLA-DR }\end{array}$ & $\begin{array}{l}\text { Anti- } \\
\text { HLA-DP }\end{array}$ & $\begin{array}{l}\text { Anti- } \\
\text { HLA-DQ }\end{array}$ & $\begin{array}{c}\text { HLA } \\
\text { Restriction }\end{array}$ & \\
\hline BM1 & 18.6 & 0.7 & 11.8 & 11.0 & DR & 96 \\
\hline BM2 & 24.6 & 0.8 & 19.8 & 19.6 & DR & 97 \\
\hline BM4 & 25.2 & 0.6 & 19.9 & 18.5 & DR & 98 \\
\hline BM8 & 14.9 & 0.6 & 10.6 & 10.5 & DR & 96 \\
\hline BM11 & 12.8 & 0.1 & 11.8 & 12.5 & DR & 100 \\
\hline BM12 & 23.8 & 0.3 & 21.2 & 24.1 & DR & 99 \\
\hline BM19 & 24.2 & 0.6 & 10.7 & 9.8 & DR & 98 \\
\hline BM21 & 11.9 & 0.1 & 9.9 & 10.0 & DR & 100 \\
\hline MA12 & 14.5 & 11.6 & 1.1 & 12.9 & DP & 92 \\
\hline MA18 & 23.3 & 12.2 & 1.0 & 12.9 & DP & 96 \\
\hline MA29 & 11.6 & 0.1 & 8.9 & 9.8 & DR & 100 \\
\hline MA35 & 19.5 & 0.2 & 16.1 & 13.2 & DR & 99 \\
\hline MA38 & 10.7 & 0.1 & 9.3 & 10.2 & DR & 99 \\
\hline MA49 & 18.9 & 0.3 & 9.6 & 11.4 & DR & 99 \\
\hline MA52 & 22.8 & 0.2 & 9.7 & 10.6 & DR & 99 \\
\hline MK12 & 19.5 & 0.3 & 11.5 & 10.8 & DR & 99 \\
\hline MK28 & 23.1 & 0.2 & 12.7 & 11.4 & DR & 100 \\
\hline MK32 & 16.9 & 0.2 & 13.3 & 12.3 & DR & 99 \\
\hline MK35 & 12.0 & 0.1 & 10.8 & 9.6 & DR & 100 \\
\hline MK38 & 16.3 & 0.2 & 11.7 & 10.8 & DR & 99 \\
\hline MK50 & 15.8 & 0.1 & 13.2 & 9.2 & DR & 100 \\
\hline
\end{tabular}

*Proliferation as correlated with $\left[{ }^{3 \mathrm{H}}\right] \mathrm{TdR}$ incorporation measured at 48 h. Results expressed as mean cpm for triplicate cultures. ${ }^{\ddagger} I n h:$ percentage inhibition $=\frac{(\mathrm{cpm} .-\mathrm{mAb})-(\mathrm{cpm} .+\mathrm{mAb})}{(\mathrm{cpm} .-\mathrm{mAb})} \times 100$ transformed B lymphocytes from the three patients were HLA serotyped, with particular attention paid to the DR serotypes. Based on the typing results, HLA-DR matched and mismatched EBV-transformed B cells were used as APC to stimulate the HLA-DR restricted TCC. The results of 15 TCC from the three patients are shown in Table III. As seen, stimulation of the clones was limited to either the HLA-DR2 or HLA-DR5 antigen. In no case did the clones respond to an APC containing the alternate nonpresenting DR molecule in combination with a mismatched HLA-DR molecule.

To further analyze the HLA associations with ABPA in a gene specific manner we extended our studies to define restriction elements among naturally occurring polymorphic alleles of the HLA-DRB1 locus representing HLA-DR2 and HLADR5. HLA-DRB1 is reported to encode the most polymorphic chain of the HLA-DR molecules. To identify the DRB1 restricting alleles, we used a panel of genotyped EBV-transformed B cells as APCs representing various alleles of HLADR2 and HLA-DR5 molecules. T cell clones were incubated with limiting concentrations of peptides or medium alone in the presence of the various APC. Analysis of the restriction pattern of each clone revealed that a single peptide can be presented by a number of allelic variants representing a particular HLA-DR molecule. The same results were obtained with the Asp f 1 protein (data not shown). Overall, two different restriction patterns were observed among Asp f 1-specific clones. Peptide recognition for some clones is restricted to a single DR allele while other clones recognize peptides in association with two or more DR alleles (Table IV). In the majority of cases the restriction crossed over into the more distantly related serotype, e.g., DRB1* 1101 and 1202, 1501 and 1601 for patients MA and BM, respectively. In these cases clonality of T cells has been proved by subcloning. The inability of some lymphoblastoid lines to induce proliferation, e.g., genotypes DRB1*1103, 1201, 1502 , and 1602, was not due to the absence of surface HLA-DR molecules since flow cytometric analyses revealed HLA-DR surface expression in these lines comparable to those that trig-

Table III. HLA-DR Restriction Determinants of Asp f 1 Specific TCC from ABPA Patients*

\begin{tabular}{|c|c|c|c|c|c|c|c|c|c|c|c|c|}
\hline & TCC & $\begin{array}{l}\text { DR2 }{ }^{\ddagger} \\
\text { DR6 }\end{array}$ & $\begin{array}{l}\text { DR3 } \\
\text { DR4 }\end{array}$ & $\begin{array}{c}\text { DR6 } \\
\text { DR11 }\end{array}$ & $\begin{array}{c}\text { DR5 } \\
\text { DR13 }\end{array}$ & $\mathrm{DR} 1^{\S}$ & DR2 & DR7 & DR4 & $\begin{array}{l}\text { DR2 } \\
\text { DR7 }\end{array}$ & $\begin{array}{l}\text { DR5 } \\
\text { DR1 }\end{array}$ & $\begin{array}{l}\text { DR2 } \\
\text { DR4 }\end{array}$ \\
\hline \multirow{6}{*}{$(\mathrm{BM}: \mathrm{DR} 2(16), \mathrm{DR} 7)^{\mathrm{I}}$} & BM1 & $14.6^{\|}$ & 0.3 & 0.4 & 0.5 & 0.4 & 18.1 & 1.8 & 0.4 & 13.9 & 0.5 & 38.7 \\
\hline & BM2 & $\overline{17.4}$ & 0.2 & 0.3 & 0.2 & 0.2 & $\overline{14.3}$ & 0.2 & 0.3 & $\overline{21.2}$ & 0.3 & $\overline{19.5}$ \\
\hline & BM4 & $\overline{19.4}$ & 0.7 & 0.6 & 0.6 & 0.6 & $\overline{18.9}$ & 1.2 & 0.6 & $\overline{25.1}$ & 0.6 & $\underline{20.2}$ \\
\hline & BM8 & $\overline{2.0}$ & 0.2 & 0.3 & 0.3 & 0.2 & $\overline{17.7}$ & 0.2 & 0.3 & $\overline{12.9}$ & 0.3 & $\overline{28.7}$ \\
\hline & BM19 & 3.6 & 0.3 & 0.4 & 0.3 & 0.3 & $\overline{25.8}$ & 0.3 & 0.5 & $\overline{12.1}$ & 0.4 & $\overline{39.0}$ \\
\hline & BM21 & $\underline{11.1}$ & 0.2 & 0.3 & 0.2 & 0.2 & $\overline{17.1}$ & 0.2 & 0.2 & $\overline{14.5}$ & 0.2 & $\overline{21.2}$ \\
\hline \multirow{4}{*}{ (MA: DR1, DR5(12)) } & MA35 & 0.3 & 0.2 & 0.3 & 11.3 & 1.0 & 0.2 & 0.2 & 0.3 & 0.2 & 23.9 & 0.3 \\
\hline & MA38 & 0.5 & 1.1 & 0.8 & $\overline{20.2}$ & 1.2 & 0.7 & 0.5 & 0.5 & 0.4 & $\underline{12.3}$ & 0.5 \\
\hline & MA49 & 0.2 & 0.2 & 0.3 & $\overline{18.2}$ & 0.3 & 0.2 & 0.2 & 0.2 & 0.2 & $\overline{14.8}$ & 0.3 \\
\hline & MA52 & 0.2 & 0.2 & 0.3 & $\underline{24.1}$ & 0.4 & 0.3 & 0.3 & 0.2 & 0.3 & $\overline{15.8}$ & 0.4 \\
\hline \multirow{5}{*}{ (MK: DR2(15), DR4) } & MK28 & $\underline{10.3}$ & 0.2 & 0.2 & 0.2 & 0.3 & 11.9 & 0.2 & 0.3 & 20.7 & 0.2 & 14.8 \\
\hline & MK32 & $\overline{14.7}$ & 0.6 & 0.6 & 0.6 & 0.5 & $\overline{11.6}$ & 0.6 & 0.5 & 5.8 & 0.6 & $\overline{10.5}$ \\
\hline & MK35 & $\overline{24.9}$ & 0.6 & 0.6 & 0.6 & 0.7 & $\overline{31.7}$ & 0.7 & 0.6 & $\overline{5.9}$ & 0.5 & $\overline{12.6}$ \\
\hline & MK38 & $\overline{10.2}$ & 0.4 & 0.5 & 0.7 & 0.4 & $\overline{20.1}$ & 0.5 & 0.5 & $\overline{9.2}$ & 0.5 & $\underline{8.7}$ \\
\hline & MK50 & $\overline{11.7}$ & 2.1 & 0.2 & 0.2 & 0.3 & $\overline{19.7}$ & 0.2 & 0.3 & $2 \overline{8.8}$ & 0.3 & $\underline{12.2}$ \\
\hline
\end{tabular}

*Allelic restriction was determined by Asp $\mathrm{f} 1$ induced proliferative responses of T-cell clones using DR-matched and DR-mismatched antigen presenting EBV-transformed B cells. ${ }^{\ddagger}$ Heterozygous APC; ${ }^{\circledR}$ Homozygous B cell lines. " [ $\left.3 \mathrm{H}\right]$ TdR incorporated, CPM $\left(1 \times 10^{-3}\right)$. "HLA-DR types of patients. 
Table IV. Proliferation of Asp f 1-specific Clones in Response to Various Peptides in the Presence of APCS Expressing HLADR2 and HLA-DR5 Subtypes*

\begin{tabular}{|c|c|c|c|c|c|c|c|}
\hline \multicolumn{8}{|c|}{ Patient MA (DR5, DRB1*1202) } \\
\hline \multirow[b]{2}{*}{ TCC } & \multirow[b]{2}{*}{ Peptides } & \multicolumn{6}{|c|}{ Genotype of DR5 ${ }^{+} \mathrm{APC}$} \\
\hline & & 1101 & 1102 & 1103 & 1104 & 1201 & 1202 \\
\hline 35 & $46-65$ & 0.4 & 0.3 & 0.4 & 0.3 & 0.5 & 11.0 \\
\hline 52 & $61-80$ & $\underline{14.6}$ & 2.0 & 1.2 & 7.0 & 1.2 & $\underline{15.2}$ \\
\hline 29 & $106-125$ & 12.4 & 0.8 & 1.2 & 3.5 & 1.1 & 8.5 \\
\hline 38 & $106-125$ & $\overline{12.6}$ & 1.1 & 0.5 & $1 \overline{1.7}$ & 0.4 & 23.3 \\
\hline 49 & $106-125$ & 0.6 & 0.7 & 0.5 & 0.5 & 0.3 & 26.6 \\
\hline
\end{tabular}

Patient MK (DR2, DRB1*1501)

\begin{tabular}{lrrrrrr} 
& & \multicolumn{5}{c}{ Genotype of DR2 $^{+}$APC } \\
\cline { 3 - 7 } TCC & Peptides & 1501 & 1502 & 1503 & 1601 & 1602 \\
\hline 28 & $46-65$ & $\underline{14.1}$ & 0.5 & 0.5 & 0.5 & 0.6 \\
35 & $61-80$ & $\underline{\underline{10.0}}$ & 1.0 & 0.5 & 0.6 & 0.6 \\
32 & $106-125$ & $\underline{11.7}$ & 0.6 & $\underline{12.7}$ & 0.6 & 0.8 \\
38 & $106-125$ & $\underline{7.0}$ & 0.5 & $\underline{11.1}$ & 0.5 & 1.1 \\
50 & $106-125$ & $\underline{10.6}$ & 0.3 & $\underline{24.6}$ & 0.5 & 0.4
\end{tabular}

Patient BM (DR2, DRB1*1601)

\begin{tabular}{ccccccc} 
& & \multicolumn{5}{c}{ Genotype of DR2 ${ }^{+}$APC } \\
\cline { 3 - 7 } TCC & Peptides & 1501 & 1502 & 1503 & 1601 & 1602 \\
\hline 8 & $46-65$ & $\underline{8.7}$ & 0.6 & $\underline{6.8}$ & $\underline{\underline{11.5}}$ & 0.8 \\
21 & $61-80$ & $\underline{8.5}$ & 0.6 & $\underline{8.7}$ & $\underline{8.0}$ & 0.3
\end{tabular}

*T cell clones $\left(3 \times 10^{4}\right)$ were stimulated with various doses of Asp f 1 peptides in the presence of $\left(3 \times 10^{4}\right)$ APCS expressing various subtypes of HLA-DR2 and HLA-DR5 in 96 well microtiter plates, for $48 \mathrm{hrs}$ at $37^{\circ} \mathrm{C}, 5 \% \mathrm{CO}_{2}$. Cultures were pulsed with $1 \mu \mathrm{Ci}[3 \mathrm{H}] \mathrm{TdR}$ for the last 16 hrs of culture period.

${ }^{\ddagger}$ Proliferative response $\left(\mathrm{CPM} \times 10^{-3}\right)$.

gered TCC proliferation (data not shown). Finally, presentation of peptide by the coexpressing DRB3 chain cannot account for the observed cross reactivity between $\mathrm{DR}^{+}$APC. All APC shared the 0202 genotype of the DRB3 chain and thus cannot explain the function for some but not others. Although the allelic variants of the co-expressed DRB5 chain on DR2 ${ }^{+}$APC are not identical, TCC stimulation cannot be explained by the presence or absence of a particular DRB5 genotype. For example, TCC (BM 8) which reacts with peptide $46-65$ can be presented in association with APC expressing DRB1* 1601 and not by DRB1* 1602 despite the co-expression of DRB5* 0202 on both variants.

\section{Discussion}

A major goal in the treatment of immunologically mediated disease is to modulate the specific $\mathrm{T}$ lymphocytes which initiate and regulate the immune response responsible for the pathophysiology of the disease. To accomplish this, it is critically important to define which subset(s) of $\mathrm{T}$ lymphocytes are activated in the disease, HLA-restriction, and epitope specificity. The aim of this investigation was to evaluate these criteria in TCC generated from ABPA patients.
The results of the TCC cytokine profiles from the ABPA patients were consistent with their lung pathology, eosinophilia, and high serum levels of IgE anti-Asp f 1 antibodies. There is abundant evidence to show that $\mathrm{T}$ cells play a key regulatory role in these processes, particularly $\mathrm{Th} 2$ cells which produce the cytokines IL-4 and IL-5 that promote both IgE formation and eosinophilia (12-15). Although all of the Asp f 1 specific TCC were isolated from peripheral blood, it is likely that these $\mathrm{T}$ cells were initially activated in the colonized lung by the Asp f 1 antigen which is produced and secreted by $A$. fumigatus. Asp f 1, a ribotoxin, is highly cytotoxic to surrounding lung tissue and thought to play a major role in the promotion of fungal colonization. Because the IgE response to Asp f 1 promotes both mast cell and eosinophil activity, the ribotoxin can potentially play a dual role in the pathogenesis of ABPA through direct cytotoxicity and indirectly by promoting IgEmediated inflammatory responses.

Marked differences were noted in the Th phenotypes between the TCC-specific for Asp f 1 and tetanus toxoid. Similar clear cut differences in cytokine profiles between PPD- and allergen-specific TCC were also found in patients allergic to airborne antigens (1-3) or infected with Toxocara canis (16). It is not clear why the response to the allergens was dominated by the Th2 subset while, in these same patients, the response to TT was skewed toward Th1 cells. This may involve the nature of the antigen and/or the route of immunization. In the case of Asp f 1, the principal locale of infection of A. fumigatus is the lung and presumably the primary site of $\mathrm{T}$ cell sensitization. Since both eosinophils as well as mast cells, known to produce IL-4, are detected in the lungs of ABPA patients $(17,18)$, activation of naive $\mathrm{T}$ cells in this milieu is likely to result in a Th2 skewed response. On the other hand, the intramuscular route of vaccination with tetanus toxoid involves priming conditions that result in a dominant Th1 phenotype. Polarization of the responding Th subset by manipulation of the priming environment has been demonstrated in a number of experimental systems. Activation of naive T cells in the presence of IL-4 favors a Th2 response while priming in the presence of IFN- $\gamma$ results in a predominant Th1 population (19-21). There is evidence that $\mathrm{T}$ cells once committed to either of the subsets continue to produce their characteristic cytokine profile on a long term basis as memory cell populations $(22,23)$. This appears to be the case in our study with at least two of the three patients. Both of the patients (BM and MA) had been in remission for long periods of time. It is likely the TCC from these patients represent long lived memory populations and as such, their presence would appear to put these patients at long term risk.

The epitope mapping results using 21 TCC from the three ABPA patients revealed the presence of at least five epitopes. The majority of the TCC (13/21) were stimulated by two peptides, 46-65 and 106-125. It will be interesting to determine whether the majority of TCC generated from Asp f 1-sensitive non-ABPA asthmatic patients respond to the same peptides 46-65 and 106-125. Perhaps the minor, or as yet unidentified epitopes, will elicit the dominant responses in these non-ABPA patients. If this were to occur, the dominant reactivity to peptides $46-65$ and 106-125 found in ABPA patients will be useful markers of this disease. Importantly, the TCC responding to these peptides will be a major target for immunotherapy. Analysis of non-ABPA and additional ABPA patients is underway to test this possibility.

With the exception of two TCC which were HLA-DPrestricted in one patient, the remainder of the identified TCC 
from the three patients were either HLA-DR2 or DR5 restricted. It is not clear whether the dominance of clones reactive to peptides $46-65$ and 106-125 is due to a relatively high affinity association of these peptides for HLA-DR2/5 or that precursor frequencies of the clones exist at higher levels in these ABPA patients due to a number of yet unidentified host determined genetic factors. Similar HLA-DR2 and DR5 restricted allergic responses to house dust mite and ragweed antigen have been reported (24-27). In addition, genetic epidemiological studies and molecular analysis of HLA class II also support a strong association between DR2 and DR5 antigens and allergic responses to ragweed and grass pollen (28-30).

We extended our studies to determine if certain structural variants of the HLA-DR2/5 serotypes representing the highly polymorphic DRB1 chain of class II molecules were associated preferentially with Asp f 1 responsiveness. In some cases the peptide presentation was restricted to only those APC expressing the host genotype (4/12 TCC), while the majority ( $8 /$ 12 TCC) were activated by more than a single allele (Table IV). For the latter, interestingly, activity by the various genotyped APC could not be predicted on the basis of their relatedness within serotypes. For example, several clones of the DRB1* 1202 genotype responded to more distinct DR5 subtypes DRB1* 1101 or DRB1* 1104, yet did not respond to more closely related genotype DRB1* 1201 (Table IV). This same pattern also occurred with TCC responsiveness to Asp f 1 in association with HLA-DR2. Similar observations have been reported (31) for peptide presentation to T-cell clones derived from a DRB1* 0402 donor and specific for HIV gp120. In those studies the cross-reactive proliferation occurred with antigen presenting cells (APC) expressing DRB1* 0403 but not with other closely related DR4 subtypes.

To dissect which variable residues individually and in combination mediate these functional differences, we analyzed key amino acid residues among the DR2/DR5 molecules. X-ray crystallography and mutagenesis studies of the HLA-DR class II molecules have ascertained a number of key amino acid residues important for antigen presentation (32-34). On the basis of those studies we have analyzed these key residues among the DR2/5 molecules which may function in Asp $\mathrm{f} 1$ presentation. Promiscuous HLA-DR2 restriction between DRB1* 1501 and 1503 alleles revealed that these functional alleles have a valine at position 86 while the nonfunctional 1502 has glycine (Table V). DRB1* 1601 which functions along with 1501 and 1503 to stimulate two TCC (Table V) is highlighted by the presence of phenylalanine at position 67 and arginine at position 71 . These particular residues are present in all HLA-DR molecules which activate DR5 restricted TCC but absent in the nonfunctional allelic variants. Since this cross reactivity is seen for several peptides it would indicate that valine at position 86 and/or the combination of phenylalanine and arginine at positions 67 and 71, respectively, constitute important TCR contact residues in Asp f 1 peptide presentation. Mutagenesis studies will ultimately determine the significance of these residues. It will be interesting to establish whether there is a significant association between ABPA and the genotypes which function in Asp f 1 antigen presentation i.e., DRB1* 1501, 1503, 1601, 1101, 1104, and 1202. Our preliminary data among a larger ABPA population indicate that there is a significant association between ABPA and the HLA-DR2 and DR5 antigens, but whether the above genotypes are key in these associations has not been determined. Studies among a larger ABPA population are now underway.
Table V. Amino Acid Residues at Polymorphic Positions in the $D R 2$ and DR5 $\beta$ Chain

\begin{tabular}{lllllllll}
\hline & $\mathbf{3 0}^{*}$ & $\mathbf{4 7}$ & $\mathbf{5 7}$ & $\mathbf{6 7}$ & $\mathbf{7 1}$ & $\mathbf{7 8}$ & $\mathbf{8 5}$ & $\mathbf{8 6}$ \\
DR2 & & & & & & & & \\
$\mathbf{1 5 0 1}^{\ddagger}$ & C & F & D & I & A & Y & V & V \\
1502 & C & F & D & I & A & Y & V & G \\
$\mathbf{1 5 0 3}$ & H & F & D & I & A & Y & V & V \\
$\mathbf{1 6 0 1}$ & C & Y & D & F & R & Y & V & G \\
1602 & C & Y & D & L & R & Y & V & G \\
DR5 & & & & & & & & \\
$\mathbf{1 1 0 1}$ & C & F & D & F & R & Y & V & G \\
1102 & C & F & D & F & E & Y & V & V \\
1103 & C & F & D & I & E & Y & V & V \\
$\mathbf{1 1 0 4}$ & C & F & D & F & R & Y & V & V \\
1201 & H & F & V & I & R & Y & A & V \\
$\mathbf{1 2 0 2}$ & H & F & V & F & R & Y & A & V \\
& & & & & & & & \\
\hline
\end{tabular}

*Denotes amino acid residue. ${ }^{*}$ Denotes genotypes of APC. Bold figures represent genotypes able to stimulate Asp f 1 -specific TCC. ${ }^{\S}$ Residues in boxes represent common amino acids among presenting APCs.

This work represents the first study to examine epitope reactivity and HLA restriction in ABPA patients. The aim of these studies was to generate information that will facilitate the design of immunotherapy and ultimately, the control of ABPA. In summary, our findings showed that the TCC derived from three ABPA patients produced high levels of IL-4 and little if any IFN- $\gamma$, and were clearly defined as Th2 cells. The majority of these TCC responded to two peptide fragments while the remainder responded to three other peptides. With two exceptions, all of the tested TCC were restricted by either the HLA-DR2 or DR5 alleles. Closer inspection revealed that a minority of the TCC were restricted solely to the allele of the host while the majority responded to at least two or more heterologous alleles within either the DR2 or DR5 subset. Thus, the information provides some initial insights into the cellular and molecular basis of the immunopathophysiology of this disease as well as possibilities of intervention. For example, cytokine therapies which abrogate Th2 responsiveness $(20,35,36)$ and the consequent nonspecific inflammatory responses merit consideration.

\section{Acknowledgments}

We thank Dr. Karla Arruda (University of Virginia, VA) for her valuable advice and generous gifts of the anti-Asp $\mathrm{f} 1$ monoclonal antibody and Af extracts as the original starting material. We extend our thanks to Dr. T. Mohanakumar (Washington University) for providing EBV-transformed B cell lines, Dr. Robert Schreiber (Washington University) for his generous gift of reagents to measure IFN- $\gamma$, and Dr. Vera Hauptfeld (St. Louis University) for HLA typing. Finally, we thank Ms. Sue Sulkey for her expert secretarial assistance and all patients who participated in this study.

This work was supported in part by National Institutes of Health Lung Disease Training grant HL-07050.

\section{References}

1. Parronchi, P., D. Macchia, M.P. Piccinni, P. Biswas, C. Simonelli, E. Maggi, M. Ricci, A.A. Ansari, and S. Romagnani. 1991. Allergen- and bacterial antigen-specific T-cell clones established from atopic donors show a different profile of cytokine production. Proc. Natl. Acad. Sci. USA. 88:4538-4542. 
2. Wierenga, E.A., M. Snoek, J.D. Bos, H.M. Jansen, and M.L. Kapsenberg. 1990. Comparison of diversity and function of house dust mite-specific T lymphocyte clones from atopic and non-atopic donors. Eur. J. Immunol. 20:1519-1526.

3. Wierenga, E.A., M. Snoek, C.J. DE Groot, I. Chretien, J.D. Bos, H.M. Jansen, and M.L. Kapsenberg. 1990. Evidence for compartmentalization of functional subsets of CD4 + T lymphocytes in atopic patients. J. Immunol. 144: $4651-4656$

4. Knutsen, A., K. Mueller, P. Hutcheson, and R. Slavin. 1994. Serum antiAspergillus fumigatus antibodies by immunoblot and ELISA in cystic fibrosis with allergic bronchopulmonary aspergillosis. J. Allergy Clin. Immunol. 93(5): 926-931.

5. Knutsen, A.P., K.R. Mueller, A.D. Levine, B. Chauhan, P.S. Hutcheson, and R.G. Slavin. 1994. Characterization of Asp f1 CD4+ T cell lines in allergic bronchopulmonary aspergillosis. J. Allergy Clin. Immunol. 94(2) Part 1:215-221.

6. Patterson, R., P. Greenberger, T. Lee, J. Liotta, E. O’Neill, M. Roberts, and H. Sommers. 1987. Prolonged evaluation of patients with corticosteriod dependent asthma stage of allergic bronchopulmonary aspergillosis. J. Allergy Clin. Immunol. 80:663-668.

7. Arruda, L.K., T.A.E. Platts-Mills, J.L. Longbottom, J.M. El-Dahr, and M.D. Chapman. 1992. Aspergillus fumigatus: Identification of 16, 18, and $45 \mathrm{kd}$ antigens recognized by human $\mathrm{IgG}$ and $\mathrm{IgE}$ antibodies and murine monoclonal antibodies. J. Allergy Clin. Immunol. 89(6):1166-1176.

8. Arruda, L., B. Mann, and M. Chapman. 1992. Selective Expression of a Major Allergen and Cytotoxin, Asp fI, in Aspergillus fumigatus. J. Immunol. 149(10):3354-3359.

9. Van Neerven, R.J.J., M.M. Van De Pol, E.A. Wierenga, R.C. Aalberse, H.M. Jansen, and M.L. Kapsenberg. 1994. Peptide specificity and HLA restriction do not dictate lymphokine production by allergen-specific T-lymphocyte clones. Immunology. 82:351-356.

10. Carballido, J.M., N. Carballido-Perrig, G. Terres, C.H. Heusser, and K. Blaser. 1992. Bee venom phospholipase A2-specific T cell clones from human allergic and non-allergic individuals: cytokine patterns change in response to the antigen concentration. Eur. J. Immunol. 22:1357-1363.

11. Higgins, J., C. Thorpe, J. Hayball, R. O'Hehir, and J. Lamb. 1994. Overlapping T-cell epitopes in the group I allergen of Dermatophagoides species restricted by HLA-DP and HLA-DR class II molecules. J. Allergy Clin. Immunol. 93(5):891-899.

12. Del Prete, G., E. Maggi, P. Parronchi, I. Chretien, A. Tiri, D. Macchic, M. Ricci, J. Banchereau, H. Spits, J.E. DeVries, and S. Romagnani. 1988. IL-4 is an essential factor for the IgE synthesis induced in vitro by human $\mathrm{T}$ Cell clones and their supernatants. J. Immunol. 140:4193-4198.

13. Sharma, S., S. Mehta, J. Morgan, and A. Maizel. 1987. Molecular cloning and expression of a human B-cell factor gene in Escherichia coli. Science (Wash. DC). 235:1489-1492.

14. Kurup, V.P., H. Choi, A. Resnick, J.H. Kalbfleisch, and J.N. Fink. 1990. Immunopathological response of $\mathrm{C} 57 \mathrm{BL} / 6$ and $\mathrm{C} 3 \mathrm{H} / \mathrm{HeN}$ mice to Aspergillus fumigatus antigen. Int. Arch. Allergy Appl. Immunol. 91:145-154.

15. Lundgren, M., U. Persson, P. Larsson, C. Magnusson, C.I.E. Smith, L. Hammarstrom, and E. Severinson. 1989. Interleukin 4 induces synthesis of $\mathrm{IgE}$ and IgG4 in human B cells. Eur. J. Immunol. 19:1311-1315.

16. Del Prete, G.F., M. de Carli, C. Mastromauro, R. Biagiotti, D. Macchia, P. Falagiani, M. Ricci, and S. Romagnani. 1991. Purified protein derivative of Mycobacterium tuberculosis and excretory-secretory antigen(s) of Toxocara canis expand in vitro human $\mathrm{T}$ cells with stable and opposite (type $1 \mathrm{~T}$ helper or type $2 \mathrm{~T}$ helper) profile of cytokine production. J. Clin. Invest. 88:346-350.

17. Kurup, V.P., S. Mauze, H. Choi, B.W.P. Seymour, and R.L. Coffman. 1992. A murine model of allergic bronchopulmonary apsergillosis with elevated eosinophils and IgE. J. Immunol. 148:3783-3788.

18. Slavin, R.G., C.W. Bedrossian, P. Hutcheson, S. Pittman, L. SalinasMadrigal, C.C. Tsai, and G.J. Gleich. 1988. A pathologic study of allergic bron- chopulmonary aspergillosis. J. Allergy Clin. Immunol. 81(4):718-724.

19. Del Prete, G., E. Maggi, and S. Romagnani. 1994. Human Th1 and Th2 cells: functional properties, mechanisms of regulation, and role in disease. [Review]. Lab. Invest. 70:299-306.

20. Gajewski, T., and F. Fitch. 1988. Antiproliferative effect on IFN-gamma in immune regulation. I. IFN-gamma inhibits the proliferation of Th2 but not Th1 murine helper T lymphocyte clones. J. Immunol. 140:4245-4252.

21. Maggi, E., P. Parronchi, R. Manetti, C. Simonelli, M.P. Piccinni, F.S Rugiu, M. de Carli, M. Ricci, and S. Romagnani. 1992. Reciprocal regulatory ef fects of IFN-gamma and IL-4 on the in vitro development of human Th1 and Th2 clones. J. Immunol. 148:2142-2147.

22. Mossmann, T.R., H. Cherwinski, M.W. Bond, M.A. Giedlin, and R.L. Coffman. 1986. Two types of murine helper T-cell clones. 1. Definition accord ing to profiles of lymphokine activities and secreted proteins. J. Immunol. 136: 2348-2357.

23. Paul, W.E., and R.A. Seder. 1994. Lymphocyte responses and cytokines. Cell. 76:241-251.

24. O'Hehir, R., D. Eckels, A. Frew, A. Kay, and J. Lamb. 1988. MHC-class II restriction specificity of cloned human T-lymphocytes reactive with Dermatophagoides farinae (house dust mite). Immunology. 64:627-631.

25. O'Hehir, R. B. Mach, C. Berte et al. 1990. Direct evidence for a functional role of HLA-DRB3 gene products in the recognition of Dermatophagoides spp. by helper T-cell clones. Int. Immunol. 2:885-892.

26. Goodfriend, L., A. Choudhury, D. Klapper, K. Coulter, G. Dorval, J. Delcarpio, and C. Osterland. 1985. Ra5G, a homologue of Ra5 in giant ragweed pollen: Isolation, HLA-DR associated activity and amino acid sequence. Mol. Immunol. 22:899-906.

27. Marsh, D., P. Zwollo, S. Huang, B. Ghosh, and A. Ansari. 1989. Molecular studies of human immune response to allergens. Cold Spring Harbor Symp. Quant. Biol. LIV:459-470.

28. Blumenthal, M., Z. Awdeh, C. Alper, and E. Yunis. 1985. Ra5 immune responses, HLA antigen and complotypes. J. Allergy Clin. Immunol. 75:155.

29. Roebber, M., R. Hussain, D. Klapper, and D. Marsh. 1983. Isolation and properties of a new short ragweed pollen allergen, Ra6. J. Immunol. 131:706-711.

30. Marsh, D., L. Freidhoff, E. Ehrlich-Kautzky, W. Bias, and M. Roebber. 1987. Immune responsiveness to Ambrosia artemisiifolia (short ragweed) pollen allergen Amb a VI (Ra6) is associated with HLA-DR5 in allergic humans. Immunogenetics. 26:230-236.

31. Olson, R.R., J.J. Reuter, J. McNicholl, C. Alber, E. Klohe, K. Callahan, R.F. Siliciano, and R.W. Karr. 1994. Acidic residues in the DR $\beta$ chain third hypervariable region are required for stimulation of a $\operatorname{DR}(\alpha, \beta 1 * 0402)$-restricted T-cell clone. Human Immunol. 41:193-200.

32. Karr, R.W., P. Panina-Bordionon, W-Y. Yu, and A. Lanzavecchia. 1991. Antigen-specific T-cells with monogamous or promiscuous restriction patterns are sensitive to different HLA-DR $\beta$ chain substitutions. J. Immunol. 146(12): 4242-4247.

33. Marshall, K.W., A.F. Liu, J. Canales, P. Barak, B. Jorgensen, R.D Gantzos, B. Aguilar, B. Devaux, and J.B. Rothbard. 1994. Role of the polymorphic residues in HLA-DR molecules in Allele-specific binding of peptide ligands. J. Immunol. 152:4946-4957.

34. Stern, L.J., J.H. Brown, T.S. Jardetzky, J.C. Gorga, R.G. Urban, J.L. Strominger, and D.C. Wiley. 1994. Crystal structure of the human class II MHC protein HLA-DR1 complexed with an influenza virus peptide. Nature (Lond.) 368:215-221.

35. Hanifin, J., L. Schneider, D. Leung et al. 1993. Recombinant interferongamma therapy for atopic dermatitis. J. Am. Acad. Dermatol. 28:189-197.

36. Boguniewicz, M., L. Schneider, H. Milgrom et al. 1993. Treatment of steroid-dependent asthma with recombinant interferon-gamma. Clin. Exp. Allergy. 23:785-790. 